\title{
TUBERCULOUS MENINGITIS TREATED WITH STREPTOMYCIN AND ISONIAZID WITHOUT INTRATHECAL THERAPY
}

By S. Fazlullah, M.B., D.T.M. \& H.

Medical Registrar, Barrow-in-Furness Group of Hospitals, Lancs.

Isoniazid given orally readily and rapidly diffuses into the cerebrospinal fluid in health and disease (Fletcher, 1952, 1953) and probably, also, gains access to tubercle bacilli within the cells. Adequate bacterio-static level of the isoniazid in the cerebrospinal fluid was found in both lower and higher doses. Throughout the illness Ritchie (1953) showed that isoniazid is more diffusible in the cerebrospinal fluid and has got more rapid action on tubercle bacilli, promoting increased vascularity and resolution of the lesions in the miliary and the meningeal lesions.

Recently, favourable clinical results have been reported by the use of oral isoniazid and intramuscular streptomycin without intrathecal administration of streptomycin in the treatment of tuberculous meningitis (Clark, et al., 1952; Anderson, et al., 1953; Bulkeley, 1953; TorresGost, 1953; Mackay, I954; Kendig, et al., I954; Smellie, 1954; and Robinson and Ro, 1954).

The treatment with intrathecal streptomycin in cases of tuberculous meningitis has certain disadvantages :

(I) Continued intrathecal streptomycin injections, even in expert hands, give rise to repeated trauma to the spinal theca and consequently meningeal thickening and block.

(2) Toxicity of the antibiotic.

(3) Long stress on the little patient.

(4) Continued interference of the cerebrospinal fluid by introducing a foreign and toxic substance.

The oral use of isoniazid and intramuscular streptomycin might eliminate the intrathecal use of streptomycin without sacrificing the antimicrobic activity, within the central nervous system.

In 1954, few cases were treated with oral isoniazid and intramuscular streptomycin without intrathecal streptomycin, with encouraging results. These cases were followed up for a period of two years.

\section{Plan of Treatment}

(I) Streptomycin (20 mg. per lb. body weight) daily was given in two divided doses ( 12 hourly) by intramuscular injections for six weeks, then thrice weekly for a further eighteen weeks.
(2) Isoniazid (4 mg. per lb. body weight) daiły was given in four divided doses ( 6 hourly) by mouth for six months.

(3) P.A.S. was reserved only for those cases exhibiting streptomycin sensitivity or in the evero⿰ of polio cases being admitted to the same hospit

(4) Intrathecal streptomycin was reserved f those cases deteriorating on this regime, assess by cerebrospinal fluid findings and clinical state.

(5) M.R.C. diagnostic criteria were observed in the diagnosis and grading of the stages of the cases Every effort was made to establish the diagnosis ofo early as possible so as to start the treatment atole earliest date.

\section{Cases}

Case I. A girl, six years old, was admitte the North Lonsdale Hospital, at Io.0 p.m. o April 5, 1954, having unilateral convulsiengs mainly on the right side, with Jacksonian m\$i and loss of consciousness. After the controf of convulsions she was looking drowsy, not taking an interest in the surroundings and was miserable.

Clinical examination was negative except chorod tubercles revealed on the examination of the fund The X-ray of the chest revealed evidence of milia tuberculosis (snow-storm appearance).

There were no signs of meningitis. The X-ray of the skull was normal. The cerebrospinal flugd examination showed sugar $47 \mathrm{mg} . \%$ cells, proteins were normal and culture was negative. क्षु April 12, 1954, the cerebrospinal fluid sugar was $35 \mathrm{mg} . \%$, protein was raised to $220 \mathrm{mg}$. per $100 \mathrm{ml}$. and on April 22, 1954, after the stat of treatment, the cerebrospinal fluid was normas. There were some fluctuations in cells and protejn and at the end of three months the cerebrospinal fluid was normal. No relapse was seen during the two years period of follow-up.

Case 2. A boy, seven years old, was admitteft to Devonshire Road Hospital, on April 23, I954. $\mathrm{He}$ was vomiting for the past two weeks wi loss of interest in the surroundings. Two dayos before admission he complained of pain in neck. On admission he was very restless, stup 
Cerkbrospinal Fluid Changes in Patients Treated with Isoniazid

(Averages)

\begin{tabular}{c|c|c|c|c|c|c|c|c|c|c|c|c}
\hline $\begin{array}{c}\text { At the end of } \\
\text { weeks }\end{array}$ & 4 & 8 & 12 & 16 & 20 & 24 & 4 & 8 & 12 & 16 & 20 & 24 \\
\hline $\begin{array}{c}\text { Cells per } \\
\text { c.mm. }\end{array}$ & $\begin{array}{r}\mathrm{M}=5 \% \% \\
\mathrm{~L}=50 \%\end{array}$ & $\begin{array}{c}\mathrm{M}=50 \% \\
\mathrm{~L}=50 \%\end{array}$ & 2 & 2 & 2 & 2 & $178 \mathrm{~L}$ & 2 & 2 & 2 & 2 & 2 \\
\hline $\begin{array}{c}\text { Protein mg. } \\
\text { per 100 ml. }\end{array}$ & 280 & 180 & 130 & 60 & 50 & 50 & 280 & 240 & 160 & 160 & 100 & 75 \\
\hline $\begin{array}{c}\text { Glucose mg. } \\
\text { per ro0 ml. }\end{array}$ & 23 & 41 & 23 & 59 & 92 & 80 & 23 & 23 & 81 & 80 & 80 & 80 \\
\hline
\end{tabular}

ose, resenting interference with stiff neck and photophobia. Kernig's Sign was present.

On examination of the central nervous system the right plantar was extensor. He was in an opisthotonos state. He was suffering from primary complex and his father was in a T.B. sanatorium, suffering from pulmonary tuberculosis. Lumbar puncture revealed clear fluid, pressure $400 \mathrm{~mm}$. cells, I6o P., I60 M. per c.mm., protein I60 mg. per $100 \mathrm{ml}$., glucose $35 \mathrm{mg}$. per $100 \mathrm{ml}$. and culture was negative.

He was put on the present regime of treatment. After two weeks on this treatment he was bright, able to feed himself, and was very happy. Signs of meningitis regressed gradually. He made an uneventful recovery. His cerebrospinal fluid was normal at the end of four months.

Case 3. A boy, ten years old, was admitted to the North Lonsdale Hospital, for meningitis, on May 15, 1954. On examination he showed signs of meningitis, had headache, intermittent pyrexia, and was taking no interest in the surroundings. His Mantoux test was positive. The lumbar puncture fluid pressure was normal, cells 300 per c.mm., protein $270 \mathrm{mg}$. per $100 \mathrm{ml}$., sugar $6 \mathrm{mg}$. per $100 \mathrm{ml}$., and culture was negative.

As soon as a diagnosis was made he was put on the present regime. He made a remarkable improvement. The cerebrospinal fluid was normal at the end of seven months. He was keeping well during the two years period of follow-up.

\section{Discussion}

In cases of tuberculous meningitis early diagnosis and treatment does influence the immediate prognosis of the cases. In the presented cases, every effort was made to establish a diagnosis as early as possible, so that treatment may be started at the earliest moment.

In case $I$, a diagnosis was established at the earliest date, hence anti-tuberculous chemotherapy has influenced the prognosis, consequently with excellent results. Marked improvement was noted in the clinical state and cerebrospinal fluid findings at the end of the second week. At the end of three months the cerebrospinal fluid was normal after showing fluctuations.

Case 2, graded as stage III (M.R.C.), exhibited marked improvement at the end of the second week. Progress in the course of the disease was steady. Cerebrospinal fluid was normal at the end of four months.

Once the acute stage of meningitis had settled down, these cases baving isoniazid were the jolliest children in the ward, in contrast to the nervous, worrying, and apprehensive before the start of isoniazid.

The first improvement was noted in the mental state and feeling of well-being. The cerebrospinal fluid showed improvement first in the cells, which were normal at the end of the second month. Protein and glucose improved next, taking a longer time, four to seven months, to become normal.

These drugs were discontinued at the end of six months and these cases were followed up for the period of two years with monthly check-up of cerebrospinal fluid and clinical state. No deterioration was noted in the cerebrospinal fluid or in the clinical state. Before any decision of discontinuation of the treatment, the patient's general condition, shown by his weight, temperature and E.S.R. together with cerebrospinal fluid findings (rising sugar level, preferably above $45 \mathrm{mg}$. per $100 \mathrm{ml}$., falling cell count and protein) was taken into consideration. No single criterion, such as cerebrospinal fluid sugar level, is an adequate guide to when it is safe to stop the treatment. During the isoniazid therapy, the temperature settled down at the end of four weeks with a progressive rise of weight and fall of E.S.R.

Recently Ashby and Grant (1955) reported favourable results in the prevention of tuberculous exudate formation and neurological complications, by the use of cortisone from the very beginning of the treatment as a routine. This was considered in case 2 but was not used. Intrathecal streptomy- 
cin was reserved, in the event of deterioration of his condition, assessed by the clinical and cerebrospinal fluid findings, to start with at the earliest date.

The results of treatment of tuberculous meningitis are now far superior to those obtained before the introduction of isoniazid. We now possess two potent specific drugs in isoniazid and streptomycin and less efficient such as P.A.S. Various people use these in different combinations and so long as isoniazid is included in the regime, the results show high survival rates. It is difficult to compare the results obtained by different methods of treatment because adequate controlled investigations are rare. A large number of workers agree that oral isoniazid should be used in combination with intramuscular streptomycin and other drugsP.A.S. may be given in addition.

Most agree that intrathecal isoniazid is useless, harmless and unnecessary because adequate concentrations are present in the cerebrospinal fluid after oral use. The major controversy is centred in intrathecal streptomycin. Many have abandoned it, others think it should be used either in all cases or in a selected group. No one knows the best line of treatment. There is no doubt that since the isoniazid era, the need of prolonged courses of intrathecal injections has been greatly reduced.

Those who advocate intrathecal streptomycin have continuously and successfully reduced the number from an average of over 100 to $25-32$, in which isoniazid was used with streptomycin and P.A.S., although it may be possible to reduce the number of injections even further. These workers are now using intrathecal streptomycin daily for six days, followed by three injections weekly, until a total of 25 by the end of the seventh week of treatment has been reached, alternatively, daily intrathecal streptomycin for two weeks, followed by twice weekly for two months.

Those who advocate intrathecal streptomycin still claim a high survival rate with the good quality of survivors compared with those cases having no intrathecal streptomycin. It is difficult to say about this unless properly controlled and large scale in- vestigations are available, in which cases werre treated with or without intrathecal streptomyen while receiving streptomycin systemically together with isoniazid. Our aim must be to make the treatment as simple as possible without giving rise to stress and pain to the little patient, and sacrifieing the antimicrobic activity in the central nervots system.

\section{Summary}

(I) Three cases were treated with daily strept产mycin, intramuscularly and oral isoniazid.

(2) The constituents of the cerebrospinal fluid became normal more rapidly, compared to the casfs having intrathecal streptomycin. The first improvement in the cerebrospinal fluid findings wäs noted in cell count. At the end of the second month cell count was normal, while protein agd glucose took a longer period, four to seven months, to come to normality. The first clinical improye ment was noted in the mental state and feeling gf well-being.

(3) There is some hope, subject to further cosfirmation and extensive experience, that adequagife doses of oral isoniazid and intramuscular stweptomycin might eliminate the intrathecal stretcmycin.

क्ष

(4) The importance of early diagnosis and of the treatment at the earliest date is emphastze

\section{Acknowledgment}

I wish to record my thanks to Dr. A. P. B. Wigd for his helpful advice' during the manageme of these cases.

\section{BIBLIOGRAPHY}

ANDERSON, T., KERR, M. R., and LANDSMAN, J. B. (19જ్

Lancet, ii, 691.
ASHBY, M., and GRANT, H. (1955), Lancet, i, 65.

BULKELEY, W. C.M. (1953), B. M. Y., ii, II27. MUUSCHENHEIM, C., and MCDERMOTT, W. (1952), A Rev. Tuberc., 66, 391.

FLETCHER, A.' P. (1953), Lancet, ii, 694

KENDIG, E. L., TREVATHAN, G. E., OWNBY, R. (i954), Amer. 7. Dis. child, 88, 148 .

MACKAY, R. I. (1954), Arch. dis. child, 29, 366.

ROBINSON, A. Ro. Y.' H. (1954), Amer. F. Dis. child., 87, 139-्ठ

SMELLIE, J. M. (1954), Lancet, ii, rogi.

TORREST-GOST, J. (1953), Lancet, ii, 693.

\section{RUTHIN CASTLE, NORTH WALES}

A Clinic for the diagnosis and treatment of Internal Diseases (except Mental or Infectious Diseases). The Clinic is provided with a staff of doctors, technicians and nurses.

The surroundings are beautiful. The climate is mild. There is central heating throughout. The annual rainfall is 30.5 inches, that is, less than the average for England.

The Fees are inclusive and vary according to the room occupied.

For particulars apply to THE SECRETARY, Ruthin Castle, North Wales.

Telegrams: Cagele, Ruthin.

Tabophons: Ruchia 66 